\title{
Ti, Zr, and Hf-based molecular hybrid materials as EUV photoresists
}

\author{
Sonia Castellanos, ${ }^{* a}$ Lianjia Wu, ${ }^{a}$ Milos Baljozovic,,${ }^{b}$ Giuseppe Portale, ${ }^{c}$ Dimitrios Kazazis, ${ }^{b}$ \\ Michaela Vockenhuber, ${ }^{\mathrm{b}}$ Yasin Ekinci, ${ }^{\mathrm{b}}$ Thomas Jung ${ }^{\mathrm{b}}$ \\ ${ }^{a}$ Advanced Research Center for Nanolithography, Science Park 110, 1098XG Amsterdam, The \\ Netherlands; ${ }^{\mathrm{b}} \mathrm{Paul}$ Scherrer Institute, 5232 Villigen, Switzerland; ${ }^{\mathrm{C}}$ Zernike Institute of Advanced \\ Materials, University of Groningen, Nijenborgh 4, 9747 AG Groningen, The Netherlands.
}

\begin{abstract}
Metal oxoclusters are hybrid inorganic-organic molecular compounds with a well-defined number of metal and oxygen atoms in their cores. This type of materials is a promising platform for extreme ultraviolet (EUV) photoresists: their inorganic cores provide them with tunable EUV absorptivity and their molecular nature might favour smaller resolution and roughness while it also renders specific spectroscopic fingerprints that allow to monitor the chemical changes induced by EUV light. In this work, we compare the EUV photochemistry of metal oxoclusters based on $\mathrm{Ti}, \mathrm{Zr}$, and $\mathrm{Hf}$ and methacrylate ligands (Mc) and their sensitivity as resist materials for EUV lithography. Decarboxylation processes upon EUV exposure are detected in all cases with ex-situ X-ray photoelectron spectroscopy (XPS) and infrared spectroscopy (IR). However, the structural changes after film deposition and after exposure differed among the three compounds. Higher sensitivity was detected for the Hf-based material than for the Zr-based analogue, in line with its higher absorptivity. XPS analyses suggest that only a small fraction of the carboxylate ligands is lost at the dose-to-gel. This change in the chemical composition is accompanied by an increased structural disorder in the layer and a rather small degree of aggregation, according to grazing incidence X-ray scattering (GIXS). These results indicate that neither a drastic loss of organic shell nor a high degree of aggregation of the naked inorganic cores are required for this type of molecular thin film to reliably operate as a resist material.
\end{abstract}

Keywords: metal oxoclusters, XPS, GIXS, EUV photochemistry, sensitivity

\section{INTRODUCTION}

With EUV lithography technology almost ready to be launched for high-volume manufacturing, there are still only few examples of photoresists offering the required performance to have an optimal industrial throughput for features of 10 $\mathrm{nm}$ critical dimension.[1-4] Ideally, a photoresist should render patterns with line width roughness (LWR) below 20\%.[4] However reaching this LWR limit usually requires a dose high enough to allow the shot-noise to be on an acceptable level. At the same time, the dose should be low enough (typically defined as as $20 \mathrm{~mJ} / \mathrm{cm}^{2}$ ) for exposure times to allow for a high number of wafers per hour to be produced at acceptable costs.

Photoresists combining metallic elements and organic moieties are arising as the most promising candidates for the next generation of photoresists.[1,3] It is generally accepted that the metallic atoms absorb a large fraction of the EUV light [5,6] while the organic part is responsible for the solubility switching properties.[7-10] In addition, the inorganic components in the photoresist provide the final patterns with good mechanical and chemical stability.[11] However, in addition to the absorptivity, other properties arising from the metallic elements can also affect the reactivity -and therefore the sensitivity- of the photoresist. Brainard's group reported a correlation between reduction potential of the central metal in oxalate complexes ( $\mathrm{Co}, \mathrm{Fe}, \mathrm{Cr})$ and their sensitivity,[10] noticing that this series of metals exhibited similar EUV cross sections. Soppera and coworkers found that $\mathrm{TiO}_{\mathrm{x}}$ nanoparticles (labeled as oxoclusters due to their small size but prepared using sol-gel chemistry) were clearly more sensitive towards deep ultraviolet (DUV) light than $\mathrm{ZrO}_{\mathrm{x}}$ and $\mathrm{HfO}_{\mathrm{x}}$ parent materials, which they attributed to the catalytic role of TiOx responsible for the fast decarboxylation and mineralization of the material.[12] Works by Ober and Giannelis have shown that both Zr oxide and Hf oxide nanoparticles rendered similar high sensitivity (in the presence of PAG), even though Hf has a higher crosssection than Zr.[13,14] Further investigations found that the sensitivity of photoresists based on Hf oxide nanoparticles towards DUV and EUV correlated to the stability of the cluster-ligand bond.[7] Therefore, it is highly relevant to elucidate what are the exact structural changes occurring right after photon absorption, determining how their efficiency

Extreme Ultraviolet (EUV) Lithography IX, edited by Kenneth A. Goldberg, Proc. of SPIE Vol. 10583,

105830A · C 2018 SPIE · CCC code: 0277-786X/18/\$18 · doi: 10.1117/12.2297167 
correlates to their molecular composition, and ultimately, optimise the materials to render a maximum solubility switch upon exposure.

In this work, the EUV photochemistry of metal oxoclusters (MOCs) based on $\mathrm{Ti}, \mathrm{Zr}$, and $\mathrm{Hf}$ and carboxylate ligands prepared as molecular compounds are investigated. Metal oxoclusters are constituted by a well-defined number of metallic atoms, bridged by $\mathrm{O}$ atoms and $\mathrm{OH}$ groups in their inorganic cores in a particular fixed arrangement.[15,16] Equally, the number of carboxylate ligands that are coordinated to the metals is also well-defined. Thus, metal oxoclusters share the core-shell structure nanoparticles. Yet, nanoparticles are usually prepared by sol-gel reactions that yield a distribution of different sizes and shapes, whereas oxoclusters are isolated as molecular crystals that result from equilibrium reactions occurring in dry conditions.

The aim of this study is to compare the photoreactivity to the EUV light and the photoresist behaviour of molecular materials with analogous chemical composition $\left(M_{x} L_{2 x}, M=\right.$ metal, $L=$ ligand) but featuring different inorganic cores. The materials were exposed to an EUV interference lithography tool and chemical changes before and after EUV exposures were inspected ex-situ by FTIR, UV-vis absorption and XPS spectroscopic methods. In addition, structural changes in the thin film, such as interparticle distance, were monitored by grazing-incidence X-ray scattering (GIXS).

\section{MATERIALS AND METHODS}

\subsection{Materials preparation and characterization}

Zr-based methacrylate MOC ( $\mathrm{ZrMc})$ is commercially available by Sigma-Aldrich. This compound consists of a core of six $\mathrm{Zr}$ atoms clustered through four bridging $\mathrm{O}$ atoms $\left(\mu_{3}-\mathrm{O}\right)$, four $\mathrm{OH}$ groups $\left(\mu_{3}-\mathrm{OH}\right)$ and through twelve carboxylate groups of methacrylate ligands, giving the molecular formula $\mathrm{Zr}_{6} \mathrm{O}_{4}(\mathrm{OH})_{4} \mathrm{Mc}_{12}(\mathrm{Mc}=$ methacrylate).[17]

Hf-based methacrylate MOC (HfMc) was synthesized following the protocol in the literature.[18] The product was identified as the hexameric oxocluster with formula $\mathrm{Hf}_{6} \mathrm{O}_{4}(\mathrm{OH})_{4} \mathrm{Mc}_{12}(\mathrm{HOBu})(\mathrm{Mc}=$ methacrylate, $\mathrm{Bu}=$ butyl) from PXRD, MS (calculated $\mathrm{m} / \mathrm{z}=2298.08[\mathrm{M}]$; found $\mathrm{m} / \mathrm{z}=2322.81[\mathrm{M}+\mathrm{Na}+2 \mathrm{H}]^{+}$), NMR, IR, and TGA. However, differences in the crystalline packing were detected from batch to batch. It must be noticed that the crystalline packing of these molecular crystals can be greatly affected by the presence of occluded such as methacrylic acid, and that the butoxide ligand can be shifted by the neighbouring monodentate carboxylate ligand.[18]

Ti-based methacrylate MOC (TiMc) was synthesized as reported in the literature.[19] The product was identified as the octamer $\mathrm{Ti}_{8} \mathrm{O}_{8} \mathrm{Mc}_{16}$ by PXRD, TGA, IR, NMR and MS (calculated $\mathrm{m} / \mathrm{z}=1872.01$; found $\mathrm{m} / \mathrm{z}=1911.94[\mathrm{M}+\mathrm{K}]^{+}$.
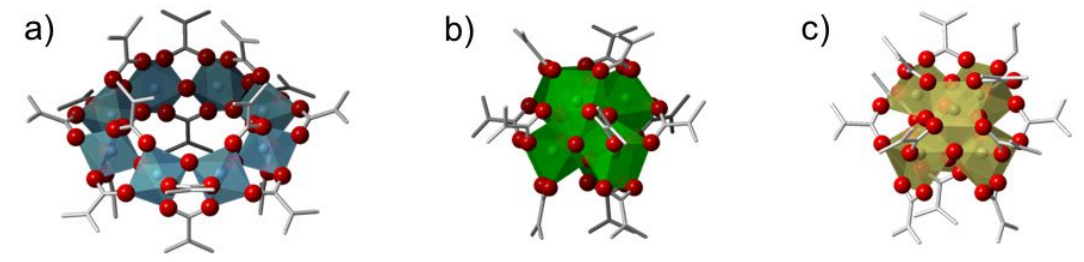

Figure 1. Represenation of metal oxoclusters used as photoresists in this work: a) TiMc, b) ZrMc, c) HfMc. Polygons represent the coordination geometry, red spheres represent oxygen atoms and grey bars $\mathrm{C}-\mathrm{C}$ bonds. Crystal structures from references [18-20].

NMR analysis was carried out using a Bruker AV-400 NMR spectrometer. The thermogravimetric analyses (TGA) were performed using a NETZSCH thermogravimetric analyzer in an $\mathrm{Al}_{2} \mathrm{O}_{3}$ crucible. Heating was performed from $35^{\circ} \mathrm{C}$ to $800^{\circ} \mathrm{C}$ at $10 \mathrm{~K} / \mathrm{min}$ in an $80 \% / 20 \% \mathrm{~N}_{2} / \mathrm{O}_{2}$ atmosphere. IR of the powder samples was performed in a Bruker ALPHA FTIR spectrometer. Powder X-ray diffraction experiments were carried out in Bruker D2 PHASER.

\subsection{Film deposition and lithography tests}

Thin films of $\mathrm{ZrMc}$ and $\mathrm{HfMc}$ were prepared by spin-coating (2100 rpm, $1 \mathrm{~min}$ ) a solution from chloroform, $\mathrm{CHCl}_{3}$, and propylene glycol methyl ether acetate, PGMEA $(9: 1 \mathrm{v} / \mathrm{v})(8.4 \mathrm{mg} / \mathrm{mL})$. TiMc thin films were spin-coated from a $\mathrm{CHCl}_{3}$ and dimethyl sulfoxide, DMSO (9:1 v/v) solution $(2100 \mathrm{rpm}, 1 \mathrm{~min})$. Post application baking for $30 \mathrm{~s}$ at $90{ }^{\circ} \mathrm{C}$ was applied to remove the remaining solvent. Samples for FTIR spectroscopy were spin-coated on double side polished Si- 
wafer $(200 \mu \mathrm{m})$. Samples for UV-vis absorption spectroscopy were spin-coated on quartz substrates. Samples for XPS analyses were spin-coated on $\mathrm{Cr} / \mathrm{Au}$ coated $(2 \mathrm{~nm} / 18 \mathrm{~nm}$ ) coverslips.

\subsection{EUV exposure}

EUV exposures were carried out at the XIL-II beamline of the Swiss Light Source (SLS) synchrotron at the Paul Scherrer Institute (PSI) with EUV light at $13.5 \mathrm{~nm}$.[21] For the open-frame experiments, $0.5 \times 0.5 \mathrm{~mm}^{2}$ or $1.7 \times 1.7 \mathrm{~mm}^{2}$ areas were exposed to EUV light through a square aperture. For the patterning experiments, a transmission mask was used providing line/space patterns with pitches of 100, 80, 60, and $44 \mathrm{~nm}$. Chloroform was used as developer.

\subsection{Post-exposure analysis}

FTIR spectroscopy of the thin films was performed in transmission mode under vacuum in a Bruker Vertex 80v spectrometer. UV-vis absorption spectroscopy was performed in a Shimadzu UV2600 spectrophotometer. XPS experiments were performed ex-situ and immediately after EUV exposure at PSI in a SPECS Analyzer Phoibos 150, with monochromatic $\mathrm{AlK}_{\alpha}$ source (energy of $1486.6 \mathrm{eV}$, power $200 \mathrm{~W}$ ).

Atomic force microscopy (AFM) images were made using a Bruker Dimension Icon, using the PeakForce tapping (ScanAsysAir) mode. The raw images were corrected for bowing using first- and second-order corrections, and the film thickness was measured by comparing the height of the film with the height of the substrate. Scanning electron microscopy (SEM) imaging was performed using a FEI Verios 460 with a voltage of $1 \mathrm{kV}$.

Grazing incidence small angle x-ray scattering (GIXS) experiments were performed both at the beamline BM26B of the European Synchrotron Radiation Facility, Grenoble (France) and at the MINA beamline at the University of Groningen (the Netherlands). An X-ray beam of about $0.3 \times 0.3 \mu \mathrm{m}^{2}$ with photon wavelength of $0.1 \mathrm{~nm}$ was used at the ESRF. The GIXS patterns where acquired using a Frelon CCD detector with a pixel size $48 \times 48 \mu \mathrm{m}^{2}$. The sample-to-detector distance was $173 \mathrm{~cm}$. At the MINA beamline, the X-ray wavelength was $0.154 \mathrm{~nm}$, the circular beam size was about 0.5 $\mathrm{mm}$ and the sample-to-detector distance was $24 \mathrm{~cm}$. The detector used was a VANTEC500 multiwire chamber with pixel size of $136 \times 136 \mu \mathrm{m}^{2}$. Images are presented with respect to the vertical $\left(q_{z}=2 \pi / \lambda\left(\sin \alpha_{i}+\sin \alpha_{f}\right)\right)$ and horizontal $\left(q_{y}=2 \pi / \lambda\left(\cos \alpha_{f} \sin 2 \theta_{f}\right)\right)$ scattering wavevector, where $\lambda$ is the X-ray wavelength, $2 \theta_{f}$ the horizontal scattering angle and $\alpha_{i}$ and $\alpha_{f}$ are the incident and vertically scattered angles.

\section{RESULTS AND DISCUSSION}

\subsection{Lithographic performance}

A critical aspect of pattern formation in inorganic photoresists with core-shell structures is irreversible aggregation[22] upon solvent evaporation during spin-coating, which can lead to important changes in the solubility of the resulting film. It had been previously observed that upon redissolution of the film made of the commercial $\mathrm{ZrMc}$ material, the individual molecular cluster could not be recovered as such.[23] In this work. we observed that upon film deposition this material seems to lose the extra carboxylic acid molecules that are not covalently bonded to the inorganic core but that are occluded in the crystalline sample.[24] Their presence in the crystalline powder sample can be detected by a weight loss around $200{ }^{\circ} \mathrm{C}$ in the TGA, and in the IR spectrum (Fig. 1a-b, C=O stretching at $1697 \mathrm{~cm}^{-1}$ and broad band between 2770 and $3515 \mathrm{~cm}^{-1}$ due to $\mathrm{O}-\mathrm{H}$ stretching of the carboxylic acid, marked with asterisk). This means that the original formulae of the powder samples are $\mathrm{ZrMc} \cdot 3 \mathrm{McOH}\left(15 \%\right.$ weight loss at $200{ }^{\circ} \mathrm{C}, 37 \%$ residue; calculated $\left.13 \%, 38 \%\right)$ and $\mathrm{HfMc} \cdot 2.5 \mathrm{Mc}\left(8 \%\right.$ weigh loss at $200{ }^{\circ} \mathrm{C}, 49 \%$ residue; calculated $\left.9 \%, 51 \%\right)$ whereas in the TiMc no extra acid was detected (33\%; calculated 34\%). We hypothesize that these extra non-coordinated ligands might stabilise the cluster in solution and in the crystalline form and that their loss in the thin films might make the clusters more susceptible to hydrolysis and/or rearrangements.

When comparing the IR spectra of the materials as powders and as thin films (Fig. 2), it was observed that the signals arising from extra free methacrylic acid (black asterisks) were barely detected, yet the broad band from 2700 to $3700 \mathrm{~cm}^{-1}$ might arise from the $\mathrm{O}-\mathrm{H}$ stretching mode of protonated carboxylic acid. The more defined band at $3670 \mathrm{~cm}^{-1}$ (red asterisk), on the other hand, is assigned to the $\mathrm{O}-\mathrm{H}$ stretching of $\mu_{3}-\mathrm{OH}$ groups bridging metallic atoms in the cluster.[25,26] It should be noticed, that for HfMc this band was only detectable in the thin film. Nevertheless, this stretching mode can shift to lower wavenumbers when the $\mathrm{OH}$ group is involved in hydrogen bonding.[25] The 
solubility of the TiMc cluster in organic solvent was poor and only films of the order of $10 \mathrm{~nm}$ thickness could be obtained thus displaying very low intensity IR absorption.
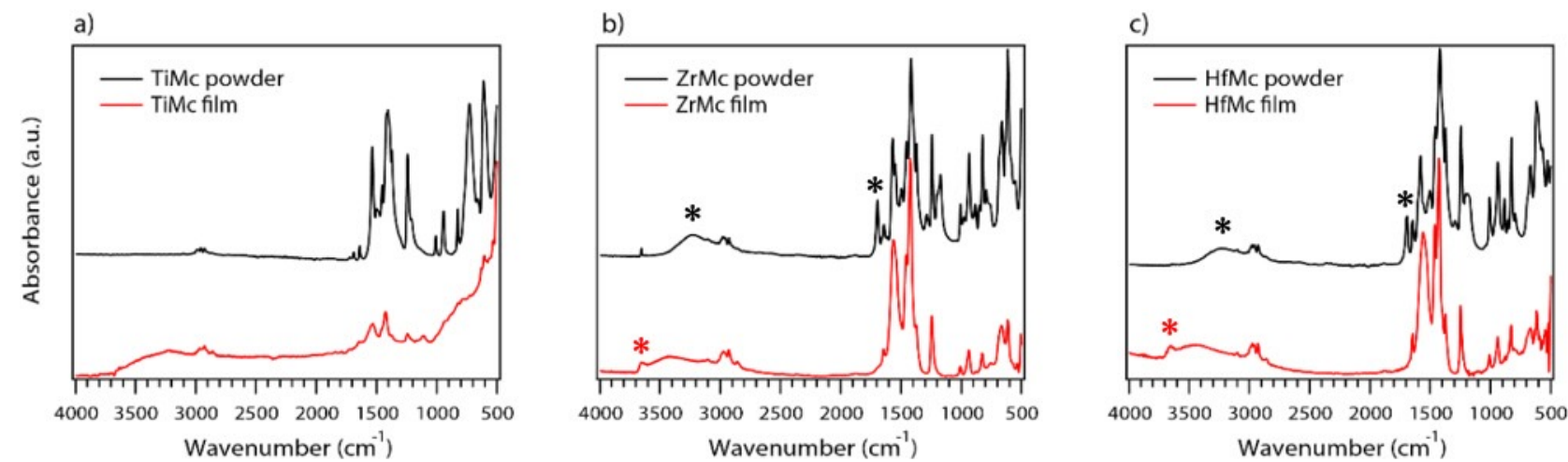

Figure 2. IR spectra of a) TiMc; b) ZrMc; c) HfMc as bulk powder (top, black) and thin film deposited on Si (bottom, red).

The lithographic performance of ZrMc and HfMc (Fig. 2a) was tested using synchrotron radiation at the SLS XIL-II end station.[21] The main goal was to compare the sensitivity of the three materials based on different metals but with the same type of chemical bonding and relate it to the reactivity of each compound. Therefore, no optimization of parameters such as post-exposure backing or development was performed and the solubility switch was mainly studied in the same solvent used for film deposition (chloroform). HfMc displayed a lower dose-to-gel $\left(20 \mathrm{~mJ} / \mathrm{cm}^{2}\right)$ than $\mathrm{ZrMc}$ $\left(34 \mathrm{~mJ} / \mathrm{cm}^{2}\right)$ and rendered a lower threshold for solubility switch $\left(3.5 \mathrm{~mJ} / \mathrm{cm}^{2} \mathrm{vs} 10 \mathrm{~mJ} / \mathrm{cm}^{2}\right)$. The sensitivity follows the experimental linear absorptivity trends, $\mu(\mathrm{HfMc})=9 \mu \mathrm{m}^{-1}, \mu(\mathrm{ZrMc})=5 \mu \mathrm{m}^{-1}$.[27] Post-exposure baking did not affect the sensitivity of the ZrMc material in both developers (chloroform and tetrahydrofuran), thus indicating that no reactive intermediate species were formed after exposure (Fig. 2b).

Contrarily, the unexposed TiMc film could not be redissolved in this solvent or other common organic solvents. This was a strong indication of the instability of this particular clusters during or after film deposition. It is known that carboxylate ligands in oxoclusters can be displaced by water or by competing chelating agents.[24] XPS analyses shown below point in this direction and thus optimisation of spin-coating and sample handling is required for this molecular material.

a)

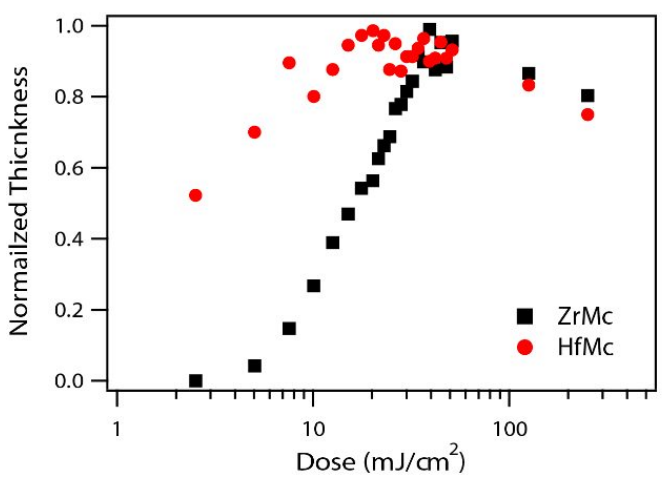

b)

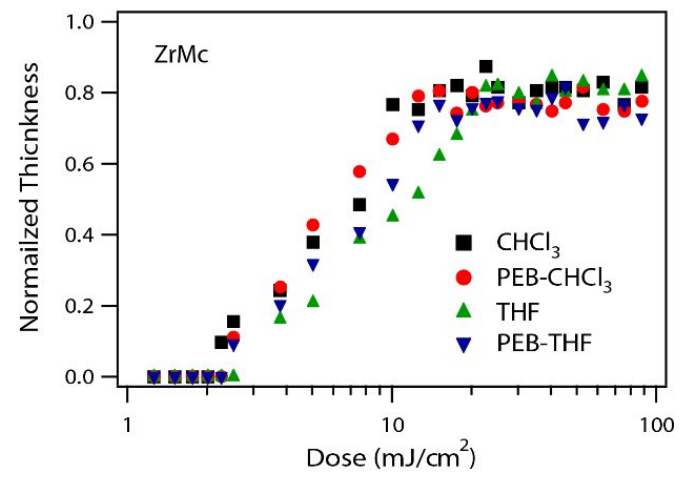

Figure 3. a) Contrast curve of ZrMc and HfMc developed with chloroform. b) Contrast curve of ZrMc before and after PEB with two different organic developers $\left(\mathrm{CHCl}_{3}\right.$ and THF).

The trends in sensitivity were also observed in dense line pattern transfer (Table 1). Formation of $50 \mathrm{~nm}$ half-pitch lines could be detected on HfMc at doses as low as $3.5 \mathrm{~mJ} / \mathrm{cm}^{2}$, indicating that a chemical change was promoted with EUV exposure. Nevertheless, the solubility contrast was poor and no lines could be resolved at higher doses. Priming the Sisubstrates with hexamethyldiasilazane (HMDS) improved the solubility contrast and allowed to attain smaller critical dimensions (22 nm half-pitch). In comparisson, lines on ZrMc could only be resolved at higher doses, both in primed and non-primed Si-substrates, yet with better solubility contrast, also at high doses. 
The detachment of large patterned areas was observed in HfMc on primed substrates (Fig. 4), thus evidencing that a complete dissolution of the unexposed areas between lines in HfMc was not successful and that the adhesion to the hydrophobic substrate was weak. Such behaviour suggests that the spin-coated material undergoes a certain structural change compared to the bulk material, which is highly soluble in $\mathrm{CHCl}_{3}$, and that the interaction of the resulting thin film is stronger with hydrophilic surfaces.

Table 1. AFM images of dense line patterns on ZrMc and HfMc.
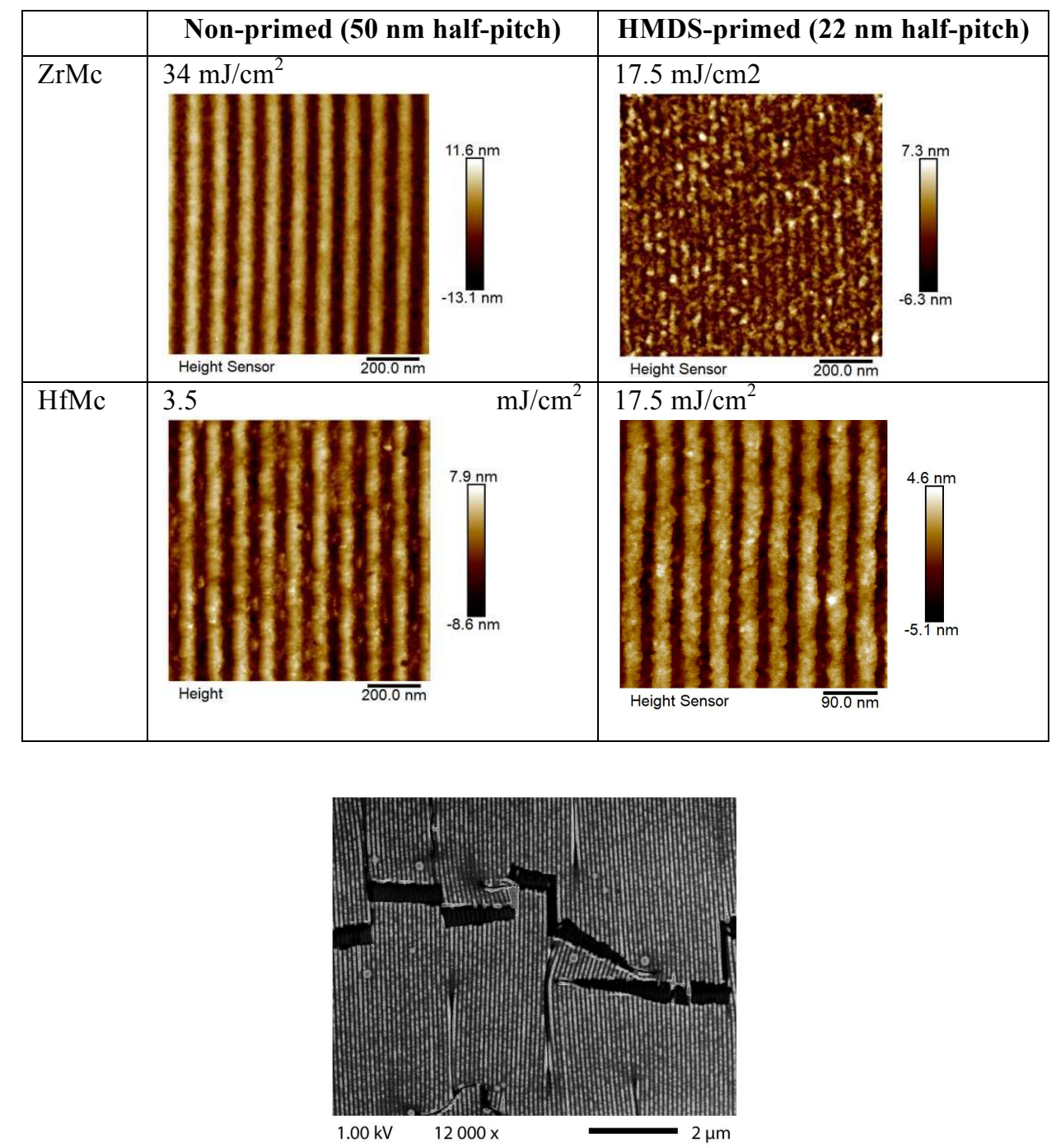

Figure 4. SEM image of $\mathrm{HfMc}$ on primed $\mathrm{Si}, 50 \mathrm{~nm}$ half-pitch, $20 \mathrm{~mJ} / \mathrm{cm}^{2}$.

\subsection{Origin of the solubility switch}

The chemical composition of the materials before and after exposure was investigated by XPS, FTIR, and UV-vis spectroscopy. The aim was to compare the reactivity of the $\mathrm{ZrMc}$ and HfMc materials and relate it to the threshold of photoconversion that renders the solubility change.

The metal/O/C elemental ratio for the unexposed films of ZrMc and HfMc was lower than expected (estimated 1:5.3:8, found 1:3:7 in both materials). This ratio might be attributed to a loss of carboxylic ligands upon deposition. It is likely that part of the carboxylate ligands rearrange to bridge clusters intermolecularly. Such arrangements had been observed in crystalline structures of this type of compounds.[20,28] Furthermore, previous studies by Ober et al. showed that 
ZrMc material after deposition cannot be recovered as a discrete molecule.[23] Inspection of the XPS high-resolution spectra for $\mathrm{O} 1 \mathrm{~s}$ allows estimating the degree of decarboxylation at the dose where solubility switch occurs. The proposed fitting (fig. 5) is based on three components assigned to $\mathrm{COO}(532 \mathrm{eV}), \mathrm{Zr}-\mathrm{O}$, such as $\mu_{3}-\mathrm{O}$ groups $(530 \mathrm{eV})$ and to $\mathrm{Zr}-\mathrm{OH}(533 \mathrm{eV})$.[29] The estimated contribution of the oxygens in the carboxylate group (COO) in the $\mathrm{O} 1 \mathrm{~s}$ peak before and after irradiation is shown in Figure 6. A partial decarboxylation was observed, in line with previously reported studies,[8] whereas a rise in the concentration of $\mathrm{Zr}-\mathrm{OH}$ species was observed.
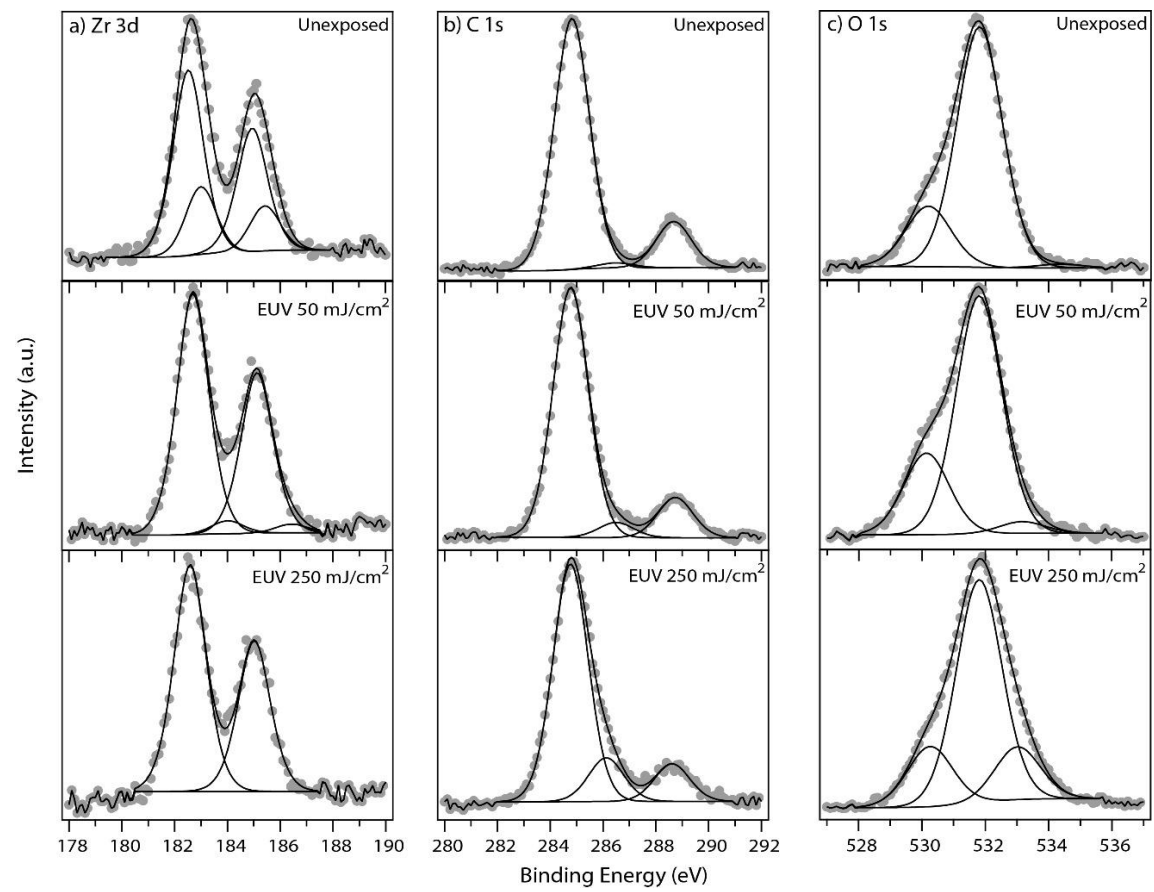

Figure 5. High resolution XPS spectra of a) Zr 3d b) C 1s and c) O 1s of ZrMc before and after EUV exposure.

Considering that the initial $\mathrm{ZrMc}$ material in the thin film contains a maximum of 12 carboxylate ligands per cluster, this would mean a maximum loss of around 1.4 carboxylate groups per cluster on average after $50 \mathrm{~mJ} / \mathrm{cm}^{2}$. The experimental EUV linear absorptivity of this material $\left(5 \mathrm{um}^{-1}\right),[5]$ implies that the transmittance of the $15 \mathrm{~nm}$ layer used for XPS is 93\%. GIXS experiments (see below) reveal that the film is still formed of clusters arranged in a disordered manner with interparticle distances similar to the crystalline packing. The number of clusters in a volume of $15 \mathrm{~nm} \mathrm{x} 1 \mathrm{~cm}^{2}$ can thus be estimated from the cluster size and crystalline density so that an average of 0.2 absorbed photon per cluster is approximated at $50 \mathrm{~nm}$ ( 1 of every 6 oxoclusters). With this assumption, a rough estimate would be that a maximum of 7 carboxylate ligands is lost over 6 oxoclusters per absorbed photon at $50 \mathrm{~mJ} / \mathrm{cm}^{2}$, a dose sufficient to induce the solubility change in ZrMc. In the case of HfMc $\left(9 \mathrm{um}^{-1}, \mathrm{~T}=87 \%\right)$, only the sample at $250 \mathrm{~mJ} / \mathrm{cm}^{2}$ was available for analysis. At this dose a loss of $19 \%$ loss of the carboxylate groups was detected. Although this numbers are rough approximations, they suggest that the degree of ligand loss is not large at doses where the solubility switch occurs.

In the case of TiMc, the $\mathrm{O}$ 1s high-resolution spectra of the fresh sample indicated that the cluster was partly hydrolysed even before exposure. This highly symmetric compound could be only dissolved with sonication in the presence of DMSO, which might induce the dissociation of the cluster. Although a solubility contrast was not attained for this material, a similar degree of decarboxylation upon EUV exposure was observed. 

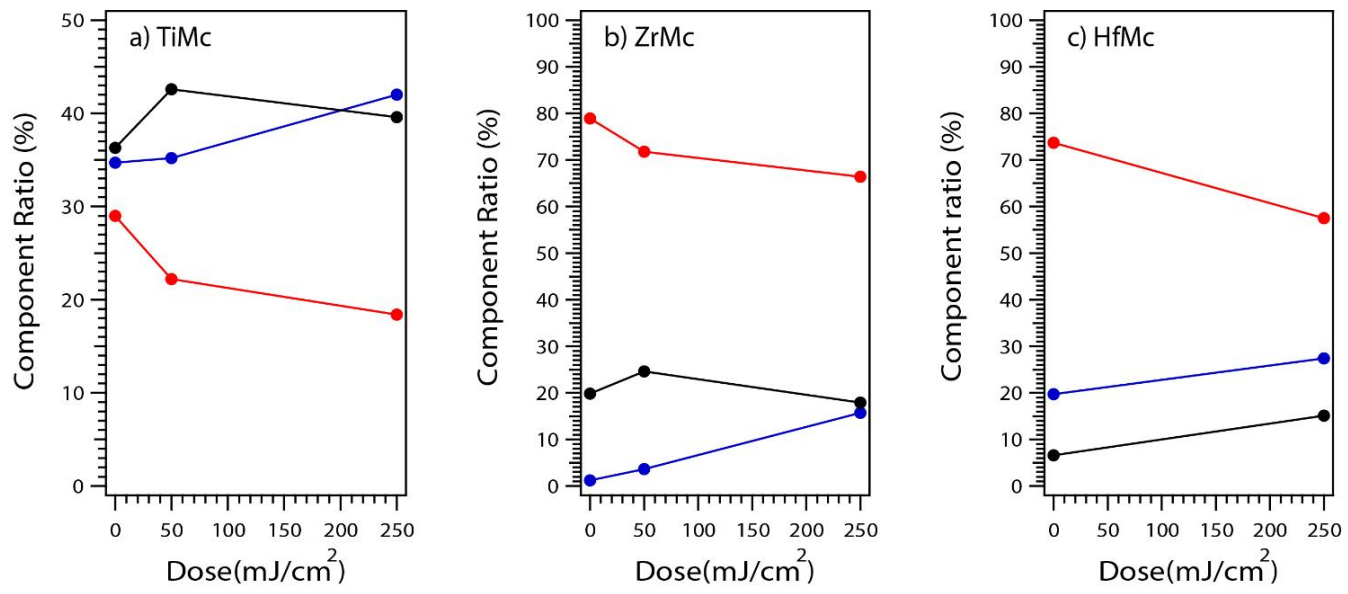

Figure 6. The ratio of different components in the $\mathrm{O}$ 1s peak in XPS for a) TiMc, b) ZrMc and c) HfMc changing with EUV doses, M-O $(\sim 530 \mathrm{eV})$ in black, $\mathrm{COO}(\sim 532 \mathrm{eV})$ in red, and $\mathrm{MOH}(\sim 533 \mathrm{eV})$ in blue.

a)

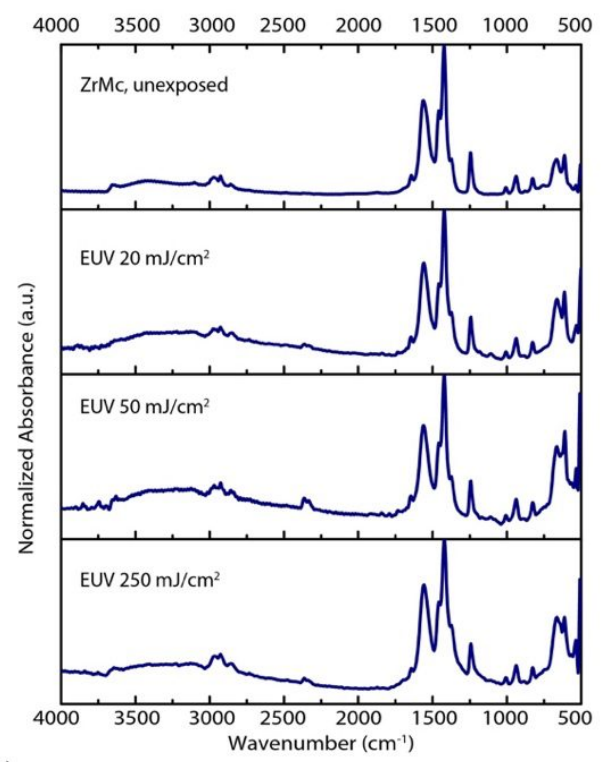

c)

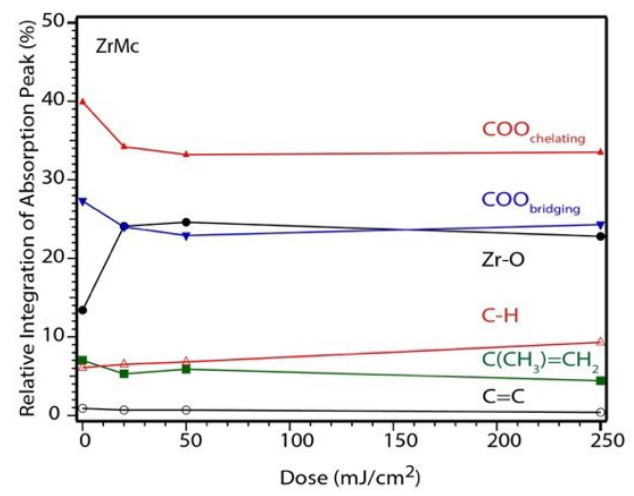

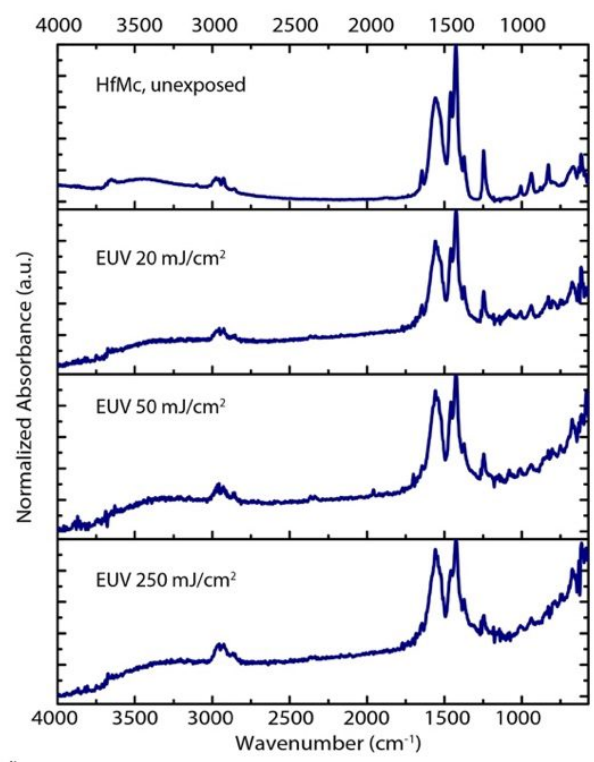

d)

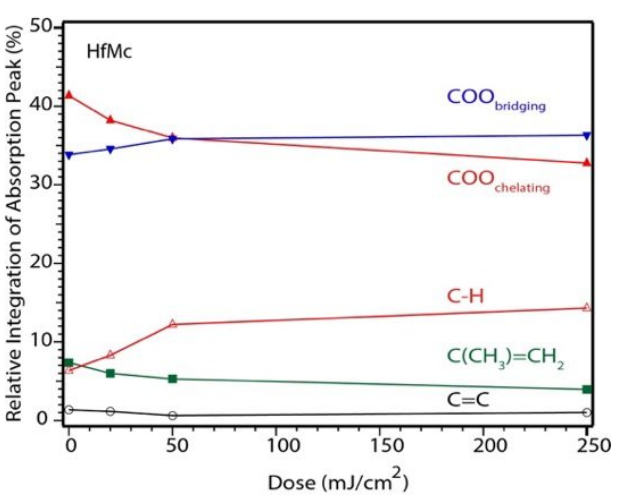

Figure 7. Normalized FTIR spectra before and after exposure to different EUV doses of a) ZrMc and b) HfMc. Relative integration values (\%) of FTIR peaks upon EUV exposure: $v_{\text {as }} \mathrm{Zr}-\mathrm{O}-\mathrm{Zr}\left(714-644 \mathrm{~cm}^{-1}\right), v_{\mathrm{s}} \mathrm{C}\left(\mathrm{CH}_{3}\right)=\mathrm{CH}_{2}\left(1246 \mathrm{~cm}^{-1}\right), v_{\mathrm{s}}$ bridging $\mathrm{COO}+v_{\mathrm{s} / \mathrm{as}}$ chelating $\mathrm{COO}\left(1334-1487 \mathrm{~cm}^{-1}\right), \quad v_{\mathrm{as}}$ bridging $\mathrm{COO}\left(1488-1634 \mathrm{~cm}^{-1}\right), v \quad \mathrm{C}=\mathrm{C}$ $\left(1643 \mathrm{~cm}^{-1}\right) \cdot[25,30,31]$ 
FTIR spectra of ZrMc and HfMc exposed materials revealed the partial bleach of the peaks attributed to the COO group stretching modes (Fig. 7). Two types of carboxylate ligands can be distinguished in ZrMc and HfMc compounds: bridging ligands, where the $\mathrm{COO}$ group binds to two different metallic atoms, and chelating ligands, where $\mathrm{COO}$ group is bound to only one metallic atom. The peaks in the region of the IR spectrum where the vibrations attributed to the chelating $\mathrm{COO}$ are expected $\left(1495 \mathrm{~cm}^{-1}, 1459 \mathrm{~cm}^{-1}\right)$ [30] decreases at a faster rate than those in the region where the vibration modes of the bridging carboxylate ligands are detected $\left(>1500 \mathrm{~cm}^{-1}\right)$. Such difference in the decrease rate is more pronounced in the case of HfMc. This trend has been reported for TiOx, ZrOx, and HfOx photoresists upon DUV irradiation,[32] and faster reaction of chelating carboxylate ligands was also proposed by Ober et al. from XPS analyses of $\mathrm{ZrOx}$ EUV photoresists.[23]

A decrease in the bands assigned to the terminal methacrylate group of the ligand $\left(v \mathrm{C}=\mathrm{C}\right.$ at $1643 \mathrm{~cm}^{-1}$ and $v_{\text {as }}$ $\mathrm{C}\left(\mathrm{CH}_{3}\right)=\mathrm{CH}_{2}$ at $\left.1246 \mathrm{~cm}^{-1}\right)$ was also detected along with the decarboxylation. The decarboxylation reaction must indeed generate an allyl unit, quite likely a radical, that could either outgas or react with the neighbouring methylene terminal groups as in radical polymerisation. It is tempting to associate the apparent increase of the $\mathrm{C}-\mathrm{H}$ stretching with the latter radical-induced reaction.

UV-vis absorption spectra (Fig. 8) are in line with the observed changes in XPS and IR spectroscopy. A bleach of the $220 \mathrm{~nm}$, attributed to electronic transitions mainly located in the methacrylate ligands $\left(\pi \rightarrow \pi^{*}\right)$, is detected. This is an indication of the decrease of terminal double bond, either due to outgassing or to reaction to yield single carbon bonds. A concomitant increase of absorption at shorter wavelength is also recorded.
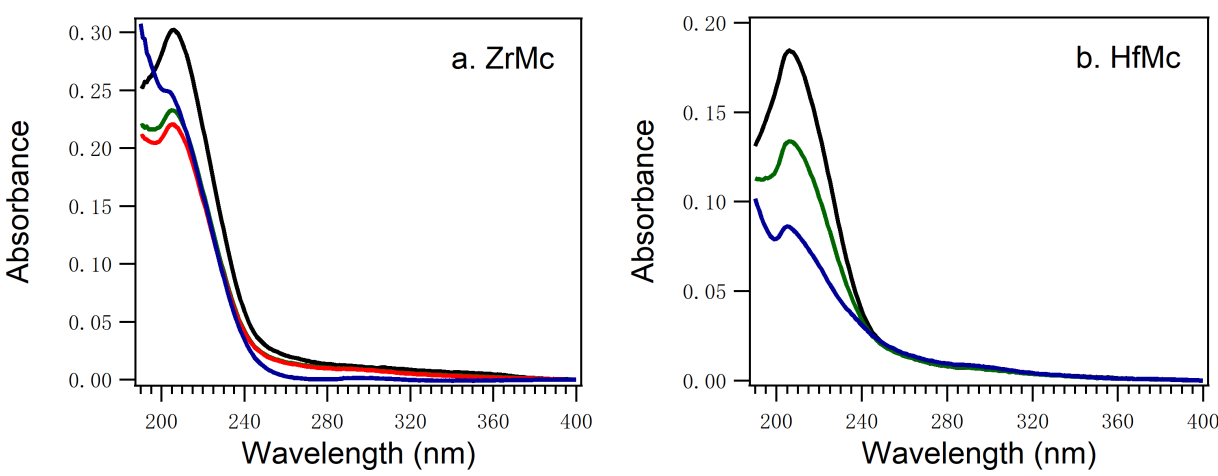

Figure 8. UV-vis absorption spectra of a) ZrMc and b) HfMc before exposure (black) and after $20 \mathrm{~mJ} / \mathrm{cm}^{2}$ (green), 50 $\mathrm{mJ} / \mathrm{cm}^{2}$ (red) and $250 \mathrm{~mJ} / \mathrm{cm}^{2}$ (blue).

In order to gain more insights into the solubility switch mechanism, the possibility of an eventual cluster aggregation was investigated in ZrMc by means of GIXS experiments. Structural changes were investigated in thin films of the insoluble material (samples exposed to 50 and $250 \mathrm{~mJ} / \mathrm{cm}^{2}$ and subsequently developed) and the soluble (unexposed) one. The GIXS patterns in Fig. 9a and 9b exhibit a single broad Debye-Scherrer like ring, suggesting that the thin film structure consists of ZrMc clusters arranged in a 3D disordered manner.[33] Nevertheless, the scattering ring shows some anisotropy suggesting a preferential packing in the direction parallel to the Si substrate, a common arrangement of disordered multi-layered nanoparticles.[34]. The average spacing among clusters along the $\mathrm{q}_{\mathrm{y}}$ horizontal direction calculated according to the Bragg's law from the position of the scattering maxima in the intensity cuts reported in Figure $9 \mathrm{~d}$ was found to be $\mathrm{d}=2 \pi / \mathrm{q}_{\mathrm{y}}{ }^{\max }=1.2 \mathrm{~nm}$ for the unexposed $\mathrm{ZrMc}$. These values are in agreement with the cluster dimensions obtained from XRD data.[20] After exposure, the scattering intensity related to the distance between neighbouring clusters becomes weaker. The intensity decrease is mostly due to the smaller areas left after exposure and development of the samples. Indeed, after normalization for the actual sample dimension along the beam path, the unexposed and exposed samples show similar scattered intensity (Fig. $9 \mathrm{~d}$ ). After the $50 \mathrm{~mJ} / \mathrm{cm}^{2}$ dose, a slight broadening and shift of the signal to $\mathrm{d}=1.4 \mathrm{~nm}$ is detected. The broadening and shift are even more pronounced after $250 \mathrm{~mJ} / \mathrm{cm}^{2}$ dose. This trend is associated with an increase in the packing disorder of the particles, i.e. a wider distribution of interparticle distances, and to a small increase of the particle size. These minor changes for both the interparticle distance and peak width observed after $50 \mathrm{~mJ} / \mathrm{cm}^{2}$ indicate that the degree of aggregation is rather small, which is in line with the low shrinking observed at the dose-to-gel in the contrast curve of this material. 
a)

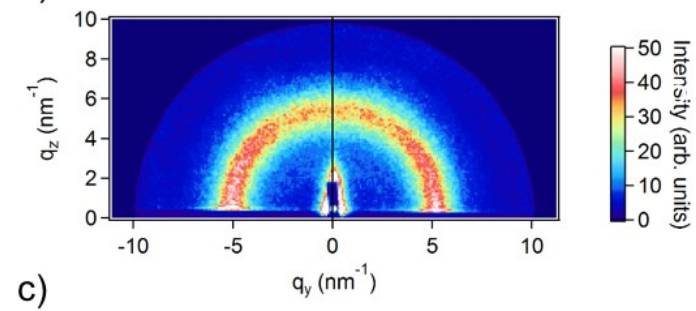

c)

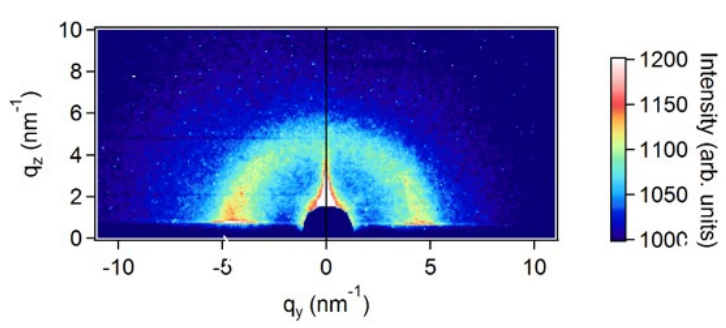

b)
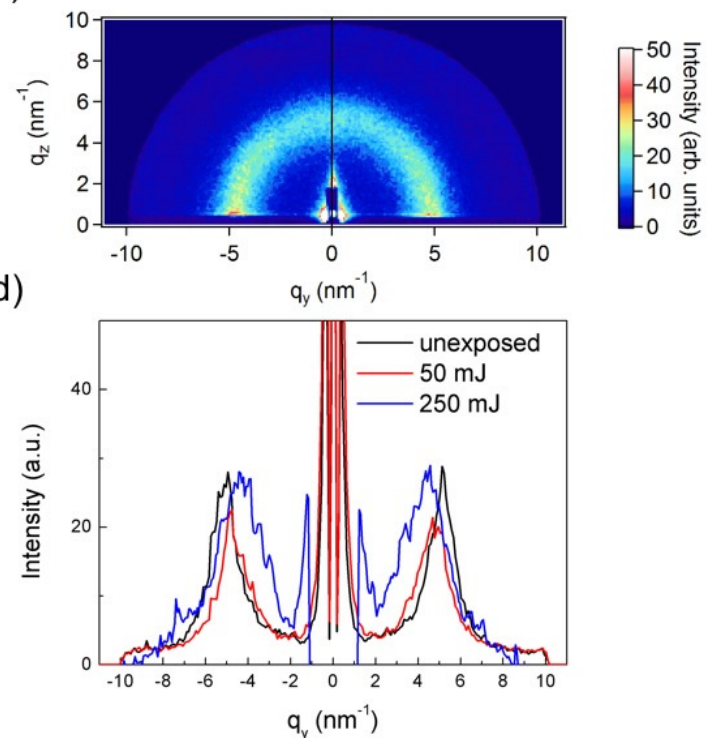

Figure 9. GIXS results for thin films of $\mathrm{ZrMc}$ a) unexposed, b) after $50 \mathrm{~mJ} / \mathrm{cm}^{2}$ exposure and development, c) after 250 $\mathrm{mJ} / \mathrm{cm}^{2}$ exposure and development; d) comparison of the horizontal intensity cuts as a function of the exposure conditions. The intensity of the cuts has been normalized with respect to the exposure time and the actual sample dimension. For all the samples the substrate is $\mathrm{Si} / \mathrm{SiO}_{2}$.

\section{CONCLUSIONS}

Metal oxoclusters based on $\mathrm{Ti}, \mathrm{Zr}$, and $\mathrm{Hf}$ and methacrylate ligands were tested as EUV photoresists. Partial loss and rearrangement of carboxylate ligands in this type of compounds can affect the solubility of the thin films after deposition. These observations highlighting the importance of the dynamic bonding between carboxylate binding groups and metal oxoclusters and demand the optimisation of the clusters stability in thin film by molecular engineering. HfMc displayed higher sensitivity than $\mathrm{ZrMc}$, thus following their absorptivity trend. Although the structural changes upon EUV exposure for the two type of clusters were similar, a higher reactivity of chelating ligands was detected in HfMc, according to ex-situ IR analyses of the thin films. X-ray photoelectron spectroscopy indicates that the loss of a small number of carboxylate groups (in the order of $12 \%$ ) is sufficient to render the solubility switch in ZrMc. This low order of decarboxylation is accompanied by an increase of disorder in the packing of the solid film, according to GIXS experiments. These results manifest that solubility switch in these material does not result from a high degree of aggregation of the inorganic cores but can be due to other structural rearrangements or to additional processes such as cross linking of the terminal alkene groups in the organic ligands.

\section{ACKNOWLEDGEMENTS}

This project has received funding from the EU-H2020 research and innovation program under grant agreement No. 654360 having benefitted from the access provided by PSI in Villigen within the framework of the Nanoscience Foundries and Fine Analysis Europe Transnational Access Activity (NFFA projects ID234 and ID269). M.B. and T.A.J. acknowledge the Swiss National Science Foundation (Grant no. 200020-153549, 200020_175800 and 206021-113149). The authors thank R. Schelldorfer for technical support in the XPS and AFM measurements. S.C and L.W. thank the support in the synchrotron experiments of Yu Zhang. 


\section{REFERENCES}

[1] P. D. Ashby, D. L. Olynick, D. F. Ogletree \& P. P. Naulleau. "Resist Materials for Extreme Ultraviolet Lithography: Toward Low-Cost Single-Digit-Nanometer Patterning," Adv. Mater. 27, 5813-5819 (2015). DOI: http://dx.doi.org/10.1002/adma.201501171

[2] H. Nakagawa, T. Naruoka \& T. Nagai. "Recent EUV Resists toward High Volume Manufacturing," $J$. Photopolym. Sci. Technol. 27, 739-746 (2014). DOI: http://dx.doi.org/10.2494/photopolymer.27.739

[3] L. Li, X. Liu, S. Pal, S. Wang, C. K. Ober \& E. P. Giannelis. "Extreme ultraviolet resist materials for sub-7 nm patterning," Chem. Soc. Rev. 2, 4855-4866 (2017). DOI: http://dx.doi.org/10.1039/C7CS00080D

[4] O. Yildirim, E. Buitrago, R. Hoefnagels, M. Meeuwissen, S. Wuister, G. Rispens, A. van Oosten, P. Derks, J. Finders, M. Vockenhuber \& Y. Ekinci. "Improvements in resist performance towards EUV HVM," Proc. SPIE 10143, 101430Q (2017). DOI: http://dx.doi.org/10.1117/12.2257415

[5] R. Fallica, J. Haitjema, L. Wu, S. Castellanos, F. Brouwer \& Y. Ekinci. "Absorption and exposure kinetics of photoresists at EUV," Proc. SPIE 10143, 101430A (2017). DOI: http://dx.doi.org/10.1117/12.2257240

[6] R. Fallica, J. K. Stowers, A. Grenville, A. Frommhold, A. P. G. Robinson \& Y. Ekinci. "Dynamic absorption coefficients of chemically amplified resists and nonchemically amplified resists at extreme ultraviolet," J. Micro/ Nanolithography, MEMS, MOEMS 15, 33506 (2016). DOI: http://dx.doi.org/10.1117/1.JMM.15.3.033506

[7] L. Li, S. Chakrabarty, K. Spyrou, C. K. Ober \& E. P. Giannelis. "Studying the Mechanism of Hybrid Nanoparticle Photoresists: Effect of Particle Size on Photopatterning," Chem. Mater. 27, 5027-5031 (2015). DOI: http://dx.doi.org/10.1021/acs.chemmater.5b01506

[8] V. Kosma, K. Kasahara, H. Xu, J. Odent \& C. K. Ober. "Elucidating the patterning mechanism of zirconiumbased hybrid photoresists," J. Micro/Nanolithography, MEMS, MOEMS 16, 41007 (2017). DOI: http://dx.doi.org/10.1117/1.JMM.16.4.041007

[9] Y. Zhang, J. Haitjema, X. Liu, F. Johansson, A. Lindblad, S. Castellanos, N. Ottosson \& A. M. Brouwer. "Photochemical conversion of tin-oxo cage compounds studied using hard x-ray photoelectron spectroscopy," $J$. Micro/ Nanolithography, MEMS, MOEMS 16, $23510 \quad$ (2017). DOI: http://dx.doi.org/10.1117/1.JMM.16.2.023510

[10] S. Grzeskowiak, A. Narasimhan, M. Murphy, L. Napolitano, D. A. Freedman, R. L. Brainard \& G. Denbeaux. "Reactivity of metal-oxalate EUV resists as a function of the central metal," Proc. SPIE 10146, 1014605 (2017). DOI: http://dx.doi.org/10.1117/12.2258151

[11] M. Trikeriotis, M. Krysaki, Y. S. Chung, C. Ouyang, B. Cardineau, R. Brainard, C. K. Ober, E. P. Giannelis \& K. Cho. "Nanoparticle photoresists from $\mathrm{HfO} 2$ and $\mathrm{ZrO} 2$ for EUV patterning," J. Photopolym. Sci. Technol. 25, 583-586 (2012). DOI: http://dx.doi.org/10.2494/photopolymer.25.583

[12] F. Stehlin, F. Wieder, A. Spangenberg, J.-M. Le Meins \& O. Soppera. "Room-temperature preparation of metaloxide nanostructures by DUV lithography from metal-oxo clusters," J. Mater. Chem. C 2, 277 (2014). DOI: http://dx.doi.org/10.1039/c3tc31326c

[13] M. Kryask, M. Trikeriotis, C. Ouyang, S. Chakrabarty, E. P. Giannelis \& C. K. Ober. "Nanoparticle Photoresists: Ligand Exchange as a New, Sensitive EUV Patterning Mechanism," J. Photopolym. Sci. Technol. 26, 659-664 (2013). DOI: http://dx.doi.org/10.2494/photopolymer.26.659

[14] C. Ober \& E. Giannelis. "New oxide nanoparticle extreme-UV photoresists achieve high sensitivity," SPIE Newsroom 2-4 (2014). DOI: http://dx.doi.org/10.1117/2.1201409.005552

[15] U. Schubert. "Cluster-based inorganic-organic hybrid materials," Chem. Soc. Rev. 40, 575-582 (2011). DOI: http://dx.doi.org/10.1039/C0CS00009D

[16] H. Assi, G. Mouchaham, N. Steunou, T. Devic \& C. Serre. "Titanium coordination compounds: from discrete metal complexes to metal-organic frameworks," Chem. Soc. Rev. 46, 3431-3452 (2017). DOI: http://dx.doi.org/10.1039/C7CS00001D 
[17] G. Kickelbick \& U. Schubert. "Oxozirconium Methacrylate Clusters: Zr6(OH)4O4(OMc)12 and Zr4O2(OMc)12 $(\mathrm{OMc}=$ Methacrylate)," Chem. Ber. 130, 473-478 (1997). DOI: http://dx.doi.org/10.1002/cber.19971300406

[18] S. Gross, G. Kickelbick, M. Puchberger \& U. Schubert. "substituted Metal Oxide Clusters Derived from Hafnium Butoxide," Monatshefte für Chemie - Chem. Mon. 1063, 1053-1063 (2003). DOI: http://dx.doi.org/10.1007/s00706-003-0031-3

[19] C. Artner, M. Czakler \& U. Schubert. "Crown-Ether-Like Structures Derived from a $\mathrm{Ti}_{8} \mathrm{O}_{8}$ (Carboxylate) 16 Metallacycle," Chem. - A Eur. J. 20, 493-498 (2014). DOI: http://dx.doi.org/10.1002/chem.201302892

[20] G. Kickelbick, P. Wiede \& U. Schubert. "Variations in capping the $\mathrm{Zr6O} 4(\mathrm{OH}) 4$ cluster core: X-ray structure analyses of $[\mathrm{Zr} 6(\mathrm{OH}) 4 \mathrm{O} 4(\mathrm{OOC}-\mathrm{CH} \quad \mathrm{CH} 2) 10] 2(\mu-\mathrm{OOC}-\mathrm{CH} \quad \mathrm{CH} 2) 4$ and $\mathrm{Zr6}(\mathrm{OH}) 4 \mathrm{O} 4(\mathrm{OOCR}) 12(\mathrm{PrOH})$ $(\mathrm{R}=\mathrm{Ph}, \mathrm{CMe}=\mathrm{CH} 2), "$ Inorganica Chim. Acta 284, 1-7 (1999). DOI: http://dx.doi.org/10.1016/S00201693(98)00251-5

[21] N. Mojarad, J. Gobrecht \& Y. Ekinci. "Interference lithography at EUV and soft X-ray wavelengths: Principles, methods, and applications," Microelectron. Eng. 143, 55-63 (2015). DOI: http://dx.doi.org/10.1016/j.mee.2015.03.047

[22] L. Li, S. Chakrabarty, J. Jiang, B. Zhang, C. Ober \& E. P. Giannelis. "Solubility studies of inorganic-organic hybrid nanoparticle photoresists with different surface functional groups," Nanoscale 8, 1338-1343 (2016). DOI: http://dx.doi.org/10.1039/C5NR07334K

[23] V. Kosma, K. Kasahara, H. Xu, J. Odent \& C. K. Ober. "Elucidating the patterning mechanism of zirconiumbased hybrid photoresists," J. Micro/Nanolithography, MEMS, MOEMS 16, 1 (2017). DOI: http://dx.doi.org/10.1117/1.JMM.16.4.041007

[24] F. Faccioli, M. Bauer, D. Pedron, A. Sorarù, M. Carraro \& S. Gross. "Hydrolytic Stability and Hydrogen Peroxide Activation of Zirconium-Based Oxoclusters," Eur. J. Inorg. Chem. 2015, 210-225 (2015). DOI: http://dx.doi.org/10.1002/ejic.201402767

[25] P. Piszczek, A. Radtke, A. Grodzicki, A. Wojtczak \& J. Chojnacki. "The new type of [Zr6( $\mu 3-\mathrm{O}) 4(\mu 3-\mathrm{OH}) 4]$ cluster core: Crystal structure and spectral characterization of [Zr6O4(OH)4(OOCR)12] (R=But, C(CH3)2Et)," Polyhedron 26, 679-685 (2007). DOI: http://dx.doi.org/10.1016/j.poly.2006.08.025

[26] V. Guillerm, S. Gross, C. Serre, T. Devic, M. Bauer \& G. Férey. "A zirconium methacrylate oxocluster as precursor for the low-temperature synthesis of porous zirconium(IV) dicarboxylates.," Chem. Commun. (Camb). 46, 767-9 (2010). DOI: http://dx.doi.org/10.1039/b914919h

[27] R. Fallica, J. K. Stowers, A. Grenville, A. Frommhold, A. P. G. Robinson \& Y. Ekinci. "Dynamic absorption coefficients of CAR and non-CAR resists at EUV," Proc. SPIE 9776, 977612 (2016). DOI: http://dx.doi.org/10.1117/12.2219193

[28] M. Puchberger, F. R. Kogler, M. Jupa, S. Gross, H. Fric, G. Kickelbick \& U. Schubert. "Can the Clusters $\mathrm{Zr6O} 4(\mathrm{OH}) 4(\mathrm{OOCR}) 12$ and [Zr6O4(OH)4(OOCR)12]2 Be Converted into Each Other?," Eur. J. Inorg. Chem. 2006, 3283-3293 (2006). DOI: http://dx.doi.org/10.1002/ejic.200600348

[29] P. C. Wong, Y. S. Li, M. Y. Zhou \& K. A. R. Mitchell. "XPS investigations of the interactions of hydrogen with thin films of zirconium oxide II. Effects of heating a $26 \AA$ thick film after treatment with a hydrogen plasma," Appl. Surf. Sci. 89, 263-269 (1995). DOI: http://dx.doi.org/10.1016/0169-4332(95)00032-1

[30] J. Kreutzer, P. Blaha \& U. Schubert. "Assessment of different basis sets and DFT functionals for the calculation of structural parameters, vibrational modes and ligand binding energies of $\mathrm{Zr} 4 \mathrm{O} 2$ (carboxylate) 12 clusters," Comput. Theor. Chem. 1084, 162-168 (2016). DOI: http://dx.doi.org/10.1016/j.comptc.2016.03.030

[31] J. Kreutzer, M. Puchberger, C. Artner \& U. Schubert. "Retention of the cluster core structure during ligand exchange reactions of carboxylato-substituted metal oxo clusters," Eur. J. Inorg. Chem. 2015, 2145-2151 (2015). DOI: http://dx.doi.org/10.1002/ejic.201403209

[32] F. Stehlin, F. Wieder, A. Spangenberg, J.-M. Le Meins \& O. Soppera. "Room-temperature preparation of metaloxide nanostructures by DUV lithography from metal-oxo clusters," J. Mater. Chem. C 2, 277-285 (2014). DOI: http://dx.doi.org/10.1039/C3TC31326C 
[33] G. Portale, L. Sciortino, C. Albonetti, F. Giannici, A. Martorana, W. Bras \& A. Longo. "Influence of metal support interaction on the surface structure of gold nanoclusters deposited on native $\mathrm{SiO} x$ / Si substrates," Phys. Chem. Chem. Phys. 16, 6649-6656 (2014). DOI: http://dx.doi.org/10.1039/c3cp54847c

[34] J. Toudert, D. Babonneau, S. Camelio, T. Girardeau, F. Yubero, J. P. Espinos \& A. R. Gonzalez-Elipe. "Using ion beams to tune the nanostructure and optical response of co-deposited Ag: BN thin films," J. Phys. D. Appl. Phys. 40, 4614-4620 (2007). DOI: http://dx.doi.org/10.1088/0022-3727/40/15/038 